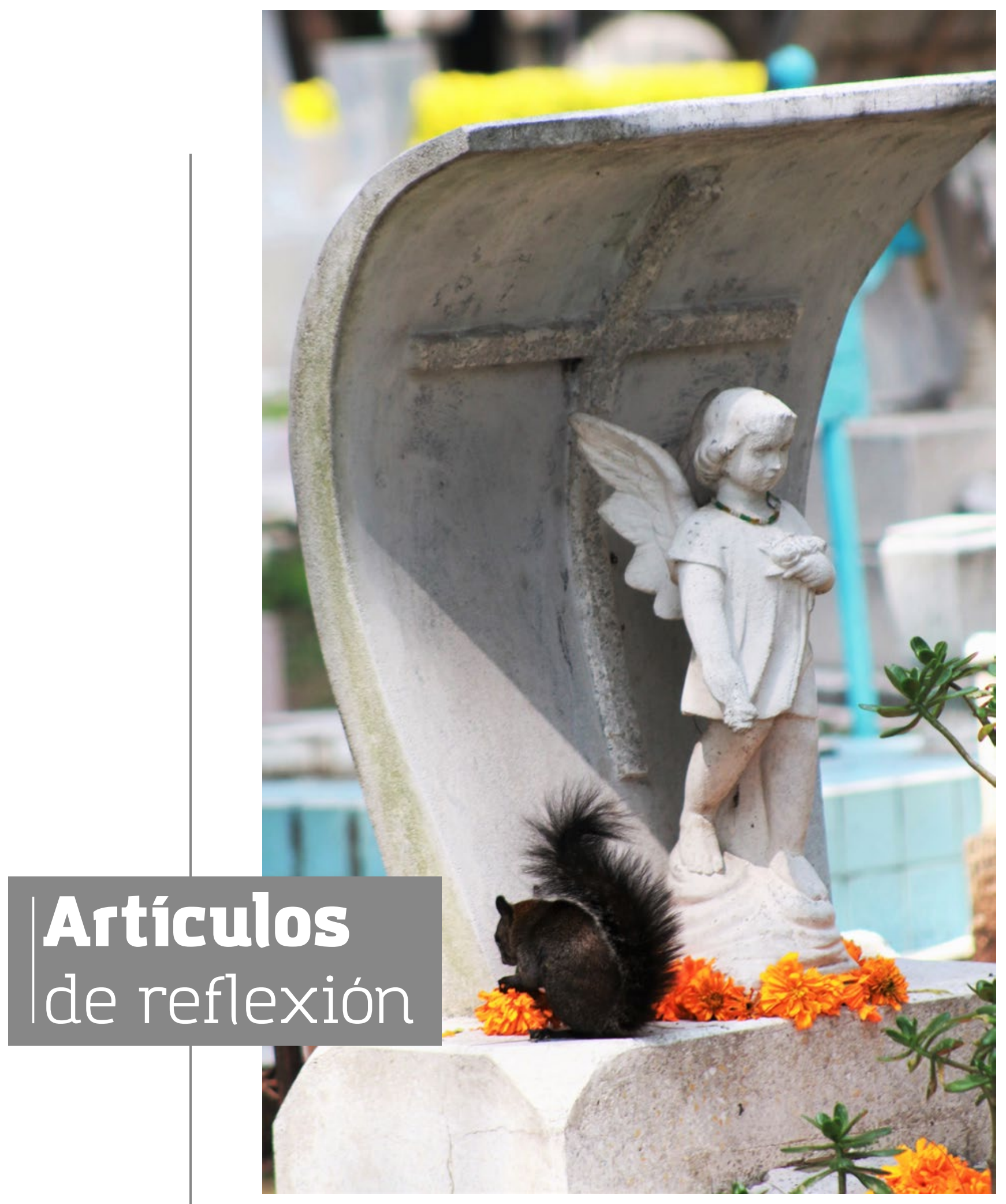




\section{Lo animal y lo femenino en los primeros 10 textos periodísticos de Gabriel García Márquez: la semilla del nobel}

\section{The animal and the feminine in the first 10 journalistic texts of García Márquez: the Nobel seed}

http://dx.doi.org/10.18566/comunica.n43.a04

Fecha de recepción: 20 de agosto de 2020

Fecha de aceptación: 13 de noviembre de 2020

\section{Resumen}

Gabriel García Márquez empezó su carrera periodística en El Universal de Cartagena con una columna llamada Punto y Aparte. Tenía 21 años y escribía sus textos en medio de la censura oficial a partir de ideas que nacían de los cables internacionales. Las 10 primeras columnas, publicadas entre el viernes 21 de mayo y el miércoles 2 de junio de 1948 son, como lo señala Héctor Feliciano, "el vivero predilecto de su lenguaje, de su hiperbólica imaginación y de su humor pícaro, orientado por una amplia curiosidad y una diversidad de temas, raras en nuestros días de desabridos observadores del mundo" (Feliciano, 2012, p. 23). A continuación se presenta un análisis textual de esas 10 primeras columnas periodísticas de Gabriel García Márquez con el fin de identificar microelementos que aluden a lo animal y lo femenino. Se trata de textos breves, donde es posible identificar numerosos elementos del universo literario de la obra posterior del nobel, que se caracteriza por la particular frecuencia con la que el autor incluye referencias al mundo animal y femenino como un recurso para inyectarles vida y corporeidad a sus obras.

\section{Abstract}

Gabriel García Márquez began his journalistic career at El Universal de Cartagena with a column called "Punto y apart". He was 21 years old and wrote his texts in the midst of official censorship, based on ideas that were comunicación

número 43

Julio - diciembre

2020 | pp.50-69

\section{Adriana}

Villegas Botero

Comunicadora social y periodista, y abogada. Magíster en Estudios Políticos de la Pontificia Universidad Javeriana. Directora de la Escuela de Comunicación Social y Periodismo de la Universidad de Manizales. Miembro del Grupo de Investigaciones de la Comunicación de la Universidad de Manizales. avillegas@umanizales.edu.co Orcid: 0000-0002-4978-3259

\section{Palabras clave}

Periodismo, periodismo de opinión, Gabriel García Márquez, periodismo literario, giro animal.

\section{Keywords}

Journalism, opinion journalism, Gabriel García Márquez, literary journalism, animal turn. 
born from international cables. The first 10 columns, published between Friday, May 21 and Wednesday, June 2, 1948 are, as Héctor Feliciano points out, "the favorite nursery of his language, his hyperbolic imagination and his mischievous sense of humor, guided by a broad curiosity and a diversity of topics, rare in our days of bland observers of the world" (Feliciano, 2012, p. 23). The work presented below consists of the textual analysis of the first 10 journalistic columns of Gabriel García Márquez, in order to identify microelements that allude to the animal and the feminine. These are brief texts where it is possible to identify numerous elements of the literary universe of the Nobel's later work, which are characterized by the particular frequency with which the author includes references to the animal and female world as a resource to inject life and corporeality into his plays.

\section{Límites y fusiones entre periodismo, literatura y vida}

En “Literaturas postautónomas 2.0", Josefina Ludmer plantea la dificultad que existe para seguir encasillando a la literatura en un campo autónomo con límites claros entre realidad y ficción y géneros específicos. Su propuesta puede leerse en clave de vida: los límites fijos aluden a textos muertos. La vitalidad de la literatura propone movimientos continuos y, como está viva, sigue reproduciéndose en formas nuevas, impuras:

Toman la forma de escrituras de lo real: del testimonio, la autobiografía, el reportaje periodístico, la crónica, el diario íntimo, y hasta de la etnografía (muchas veces con algún "género literario" injertado en su interior: policial o ciencia ficción por ejemplo). No se sabe si los personajes son reales o no, si la historia ocurrió o no, si los textos son ensayos o novelas o biografías o grabaciones o diarios (Ludmer, 2009).

Incluye Ludmer (2009) dentro de su enumeración el testimonio, el reportaje periodístico y la crónica, y abre con ello un boquete por el cual es posible estudiar aún más campos de hibridaciones; así como tradicionalmente se ha fijado una frontera entre realidad y ficción, hay también en el campo del periodismo, que en principio se ubica en la orilla de la realidad, otro límite que pareciera incuestionable: el de los géneros informativos (noticia, reportaje) versus los géneros de opinión (columna, glosa, editorial, obituario, etc.). La crónica suele entenderse como la bisagra que une las dos fronteras.

Evando Nascimento (2016) critica el texto de Ludmer y advierte que "ampliar es, entre otras cosas, dar elasticidad a un cuerpo; no es destruir sus límites sino ponerlos en cuestión, haciendo a tal cuerpo desdoblarse en otros sentidos" (2016, p. 51). En este sentido, resulta interesante analizar 
las columnas de opinión iniciales del nobel Gabriel García Márquez con el fin de desdoblarlas para hacer una lectura literaria de textos periodísticos que dinamitan las fronteras tradicionales entre realidad y ficción y entre información y opinión.

El joven García Márquez tenía 21 años cuando el 9 de abril de 1948 estalló el Bogotazo. En ese entonces se aburría como estudiante de Derecho en la Universidad Nacional, vivía en una pensión del centro de Bogotá y quería dedicarse a escribir, pues ya había logrado la publicación de tres cuentos en El Espectador: en septiembre de 1947 había aparecido "La tercera resignación"; en octubre del mismo año había publicado "Eva está dentro de su gato", y en enero de 1948 había salido "Tubal Caín forja una estrella". Abandonar la universidad para dedicarse a escribir no era una decisión fácil: era el hijo mayor de una familia que soñaba con un profesional que los sacara de la pobreza. Desertar de sus estudios no era una opción, pero el destino se le apareció en forma de cataclismo: el Bogotazo, desatado por el asesinato del líder liberal Jorge Eliécer Gaitán, destruyó buena parte del centro de la capital colombiana, produjo una cantidad de muertos que algunos estiman en 3000, hubo numerosos incendios y la universidad en la que estudiaba García Márquez cerró sus puertas.

Ante un panorama tan dantesco abandonó la ciudad y viajó a Cartagena, donde pocos días después el escritor Manuel Zapata Olivella le contó que el hermano del poeta conocido como el Tuerto López, el liberal Domingo López Escauriaza, había fundado en marzo un diario que se llamaba El Universal, cuyo jefe de redacción era Clemente Manuel Zabala, y acordó una cita que significó la incursión de García Márquez en el mundo periodístico.

El 21 de mayo de 1948 apareció en la página 4 de El Universal de Cartagena la primera de 38 columnas Punto y Aparte, que al principio fueron diarias y luego cada vez más espaciadas en el tiempo, hasta que el 10 de julio de 1949 apareció la última. Desde el punto de vista formal, los textos de Punto y Aparte son columnas de opinión: se publicaban en la página 4, donde aparecían el editorial y las columnas. Eran artículos con una extensión entre las 270 y 500 palabras, con un diseño tipográfico que incluía siempre el nombre de la columna antes del lead o primer párrafo. Curiosamente, ninguna de las columnas escritas por el nobel en esta época lleva título.

No obstante, en sentido estricto no se trata de columnas de opinión. No fijan una posición política sobre un tema de coyuntura ni presentan el desarrollo de argumentos para explicar una hipótesis o idea sobre un hecho de interés público y actual. Son columnas de opinión en el estilo muy libre de Luis Tejada, pero no en el estilo beligerante y partidista de la mayoría de 
los columnistas de esa convulsionada época política que tenían tribuna en la gran prensa nacional.

Gerald Martin las define como crónicas (Martin, 2012, p. 32) y algo similar considera el escritor Héctor Abad Faciolince (2012):

No son, en rigor, columnas de opinión; no se manifiestan de un modo tajante sobre ningún acontecimiento político o violento de la realidad del país. Son, más bien, paseos de la imaginación y divagaciones sobre cosas graves o livianas que parecen flotar en el aire (Abad, 2012, p. 91).

Jacques Gilard las define como comentarios humorísticos:

La época costeña de García Márquez forma un todo porque, independientemente de que es un período decisivo de formación y de definición de opciones (todo ello, además, en un marco geográfico y humano bien caracterizado), su actividad periodística se desarrolla dentro de un género específico que es el del comentario en su modalidad humorística (...) Se trataba de llenar un espacio, de decir cosas - a veces muchas cosas- a propósito de poco o de nada. Entonces todo venía a ser cuestión de estilo: de manera de decir las cosas y también de manera de plantearlas, con lo cual se amplía bastante la estrecha noción de estilo (Gilard, 1981, p. 43).

La dificultad para ubicar con claridad el género al que pertenecen estos textos germinales del nobel trasciende las fronteras del periodismo. Se trata de artículos elaborados al fragor de la velocidad del diario e incluyen no solo elementos de ficción, o al menos de la afiebrada imaginación del autor, sino que además utilizan con notoria frecuencia alusiones al mundo animal y femenino, sin tener como protagonistas a los animales o a las mujeres. Es decir: el futuro nobel descubre que para llenar de vida sus escritos resultan útiles las referencias y reflexiones sobre el cuerpo, los animales (particularmente las aves), la maternidad, la fertilidad y la voluptuosidad. Estas alusiones marcan el estilo de estos 10 textos primigenios y pueden rastrearse en su creación literaria posterior.

\section{La semilla literaria del universo garciamarquiano}

En su ensayo "Periodismo, ficción, espacio carnavalesco y oposiciones binarias: la creación de la infraestructura novelística de Gabriel García Márquez", el profesor de la Universidad de Virginia Robert L. Sims estudia los microelementos y macroelementos que se identifican en las columnas conocidas como Jirafas, publicadas por García Márquez en El Heraldo a partir de 1949, luego de haber publicado las 38 columnas de Punto y Aparte. Dice el profesor: 
Estos microelementos forman parte de la materia prima del mundo novelístico que García Márquez estaba en vías de desarrollar en serio a partir de 1950 (...) Aunque García Márquez no alcanzó a escribir La casa en aquel momento, ya tenía lo esencial para su futura obra maestra, Cien años de soledad. Lo que sí le faltaba era precisamente la infraestructura de macroelementos que le hubieran permitido integrar los ya existentes microelementos. Los macroelementos, o unidades constitutivas, ya existían no como relaciones aisladas sino como haces de relaciones en las jirafas que escribió García Márquez entre 1950 y 1952 (Sims, 1988, p. 51).

Con esa premisa, el profesor Sims examina cuatro oposiciones binarias que identifica en las Jirafas: a) espacio carnavalesco / espacio oficial; b) tiempo cíclico-mítico / tiempo histórico-lineal; c) discurso dialógico / discurso monológico; y d) sociedad humana / sociedad espectacular-especular (Sims, 1988, p. 51).

Con base en este antecedente se realizó un análisis textual para identificar algunos microelementos recurrentes en los primeros 10 textos periodísticos de García Márquez, escritos en un lapso de dos semanas, relacionados con las referencias al mundo animal y femenino, que son una especie de abrebocas del estilo que iba a desarrollar en el universo literario que estaba por crear. Como se trata de textos sin título se identifican por su frase inicial. Llama la atención que los primeros 10 textos periodísticos del nobel en El Universal contienen todos, sin excepción, referencias al mundo animal. En algunos, como el que se refiere a los espantapájaros, la alusión se da de un modo natural, pero en casi todos los demás, cuyo tema central no tiene relación, al menos directa, con la naturaleza, la alusión aparece como figura literaria. De todos los animales mencionados, las aves tienen una figuración recurrente, aunque no exclusiva, en los textos analizados, lo cual puede tener alguna relación con el interés del autor caribeño en la música: en unas cuantas ocasiones se refiere a aves para explicar un sonido.

Algo similar ocurre con las referencias directas al universo femenino, que aparecen en ocho de las 10 primeras columnas. En el caso del texto relacionado con la nueva moda de las faldas largas, la relación es evidente, pero en los demás las alusiones a lo femenino se presentan usualmente como figuras literarias. En estos textos iniciales García Márquez destaca la figura de la matrona o la abuela y hace permanentes referencias al vientre, la gravidez y el parto. El autor reivindica la fuerza por encima de la tradicional visión de la debilidad de la mujer, pero es una lectura previa a la revolución de los años 60, que entraría a reclamar un universo para la mujer por fuera del rol de la maternidad. 


\section{Los habitantes de la ciudad nos habíamos acostumbrado... (El Universal, viernes 21 de mayo de 1948)}

El tema del texto es el toque de queda, que después de varias semanas ha llegado a su fin. En un largo y único párrafo de 270 palabras, escrito en pasado, García Márquez habla del silencio que cae sobre la ciudad amurallada luego del anuncio del inicio del toque de queda por la "garganta metálica" hacia las 12:00 de la noche. Sin mencionar nombres propios ni decretos, el texto es una rebelión contra una orden que prohíbe la circulación durante la madrugada y, en consecuencia, "doblaba nuestra libertad". La condena de los ciudadanos al encierro lo lleva a rememorar la época del asedio de la ciudad por el pirata Francis Drake.

Sobre ese primer texto en El Universal, el autor narró en Vivir para contarla que cuando se la mostró a Clemente Manuel Zabala, él le dijo:

No está mal, pero es imposible publicarlo· (...) La nota que se publicó por fin en la página editorial no tenía nada que ver con lo que yo había escrito. Entre los remiendos del maestro Zabala y los del censor, lo que sobró de mí fueron unas piltrafas de prosa lírica sin criterio ni estilo y rematadas por el sectarismo gramático del corrector de pruebas (García Márquez, 2002, p. 388).

Con relación a este primer texto, explica Jacques Gilard (1981):

La nota inaugural de su carrera de periodista - que ya revelaba también su problemática temporal de escritor- es un anuncio de los excesos sangrientos del sectarismo político que aún distaba mucho de alcanzar su clímax y una clara asimilación entre la ideología del poder colombiano de entonces y de las potencias del Eje (tampoco es inocente, estando en Cartagena, la alusión a Francis Drake) (Gilard, 1981, p. 50).

El profesor Fabio Rodríguez Amaya (2015) señala:

Es una nota melancólica, con el fin de esquivar la censura, pero diciendo lo que debe decir sobre las condiciones políticas de Colombia: agobiada por la violencia, el estado de sitio y con campanas que al repicar anuncian en Cartagena la restauración de la república criolla conservadora, alineada con nazistas y fascistas del eje que al joven periodista le resultaba inadmisible (Rodríguez, 2015, p. 35).

Este primer texto periodístico incluye tres referencias explícitas al mundo animal: se refiere al reloj de la Boca del Puente en "su irreemplazable sitio de animal doméstico"; luego dice que "quedó sonando en el oído como un pájaro eterno" y por último señala que "se adelantaba al nuevo día como 
otro gallo grande". Las tres referencias animales están conectadas con giros sonoros o acústicos y con ellas el autor refuerza la idea que quiere comunicar: una ciudad que ya se ha acostumbrado (domesticado) a la restricción de la libertad que implica el toque de queda.

El animal cumple acá un papel específico de evocación sonora (el gallo, el pájaro eterno), que se refuerza con otros elementos acústicos que incluye el autor: "Diariamente, a las doce, oíamos allá afuera la clarinada cortante"; “... Caía entonces sobre la ciudad amurallada un silencio grande, pesado, inexpresivo. Un silencio duro", para rematar aludiendo a "ese silencio hondo, imperturbable, que antecede a las grandes catástrofes".

Este texto carece de alusiones específicas al mundo femenino, pero sí incluye referencias al cuerpo humano: habla del silencio que "se iba metiendo en cada vértebra, en cada hueso del organismo humano, consumiendo sus células vitales, socavando su levantada autonomía", en una construcción literaria que se relaciona con el biopoder descrito por Foucault, quien descubre que "las técnicas de sujeción y de normalización de las que surge el individuo moderno tienen como punto de aplicación primordial el cuerpo" (Giorgi y Rodríguez, 2007, p. 10).

\section{La madrugada -en su sentido poético-... (El Universal, viernes 21 de mayo de 1948)}

Dado que los textos de opinión de la columna Punto y Aparte no llevan título, este segundo texto, publicado el mismo día y en el mismo espacio del primero (uno a continuación del otro), puede entenderse como una segunda columna de opinión o como una continuación de la primera. Por su extensión, 390 palabras, puede leerse como una columna autónoma e independiente, con sentido en sí misma. Por su tema puede asumirse como una continuación de una única y larga columna. De ahí que algunos autores hablen del texto siguiente, sobre los acordeones, como el segundo y otros como el tercero.

En tres párrafos García Márquez se ocupa de las seis horas que transcurren entre la medianoche, cuando comienza el toque de queda, y el amanecer. Alude a las madrugadas descritas por los abuelos, cuando "se escuchaba en el patio el rumor que dejaba el azúcar cuando subía a las naranjas" y establece un contraste, introducido por el toque de queda, entre esa calma y la madrugada dura de Londres, Varsovia o "los ojos asombrados de los niños alemanes", sin mencionar de manera explícita la Segunda Guerra Mundial ni a ninguno de sus protagonistas.

Sobre este texto escribe Juan Villoro lo siguiente: 
Imaginar el antecedente ficticio de lo auténtico es un gesto intelectual equivalente a fabular lo real. Para la verosimilitud de la lectura, lo importante es que el texto responda por su propia legalidad y sea visto como si las cosas no pudieran ocurrir de otro modo. Por eso, el cronista se afana en borrar las costuras entre la noticia y su exacerbación, es decir, su desarrollo inverificable pero posible (Villoro, 2012, p. 131).

Desde el primer párrafo el texto incluye una referencia al mundo femenino, como soporte de un universo personal: "Habíamos oído hablar a nuestras abuelas que nos decían no sé qué cosas fantásticas de aquel olvidado pedazo del tiempo". Se trata de una alusión ligada, como en el caso anterior, al giro acústico, en este caso a la voz de las abuelas, entendidas ellas como un colectivo que conecta con el pasado remoto.

Esta concepción del mundo femenino que irrumpe al comienzo de esta columna se relaciona con una confesión del autor incluida en su autobiografía Vivir para contarla: “... la vida me ha permitido sentirme más cómodo y seguro entre ellas que entre hombres. También de allí puede venir mi convicción de que son ellas las que sostienen el mundo, mientras los hombres lo desordenamos con nuestra brutalidad histórica" (García Márquez, 2002, p. 89). Se trata de una visión de las mujeres como un conjunto, más que como individualidades diversas. Mujeres que son fortalezas, como Úrsula Iguarán, Fermina Daza o Sierva María de Todos los Ángeles.

Esta segunda columna incluye otras tres nuevas alusiones al mundo animal: al hablar del amanecer, el autor menciona "el grillo, el grillo exacto, invariable, que desafinaba sus violines", en clara conexión con el sonido que emiten. Una segunda: "Los peces de colores tienen que abrirles el agua a los submarinos con esta civilización de pólvora y clarines", donde el autor habla de las batallas navales de la Segunda Guerra Mundial. La columna termina con una referencia al animal domesticado que se ha acostumbrado al toque de queda y que ya apareció en el primer texto: "Nos iremos a dormir mansamente -extraños animales contradictorios".

\section{No sé qué tiene el acordeón de comunicativo... (El Universal, sábado 22 de mayo de 1948)}

Con 477 palabras distribuidas en cuatro párrafos de extensión irregular, García Márquez construye en este texto una declaración de amor al acordeón y al vallenato que no menciona de manera explícita, pero insinúa al hablar del "folklore nacional al lado de las gaitas, de los millos. y de las tamboras costeñas". La columna se refiere al origen alemán del acordeón, su paso por Francia, su mutación argentina en bandoneón y el vigor que tiene en el presente en el valle del Magdalena, aunque "no le faltan enemigos". 
Sobre este texto comenta Gerald Martin (2012), biógrafo del nobel:

El artículo es igualmente provocador a su manera: declara su identificación con la cultura de su región y, específicamente, su cariño por el acordeón, que es mestizo (aunque no lo dice explícitamente), "ilegítimo" ("bastardo", incluso), "proletario", "bohemio" y "vagabundo", todo un paquete. Y todo un camino (Martin, 2012, p. 33).

Es en este artículo, publicado en su segundo día en El Universal, en el que García Márquez hace doble referencia a las greguerías creadas por Ramón Gómez de la Serna. Al analizar los textos publicados el 21 de mayo y este publicado el 22, Martin (2012) concluye lo siguiente:

Su primer artículo arranca con una referencia política, e, implícitamente, con un rechazo a la clase política dominante en Colombia; el segundo comienza con una referencia a la cultura popular contrapunteada con la alta cultura (la referencia a las "greguerías" o juegos de palabras inventados por el escritor español de vanguardia Ramón Gómez de la Serna). Es impresionante constatar que estos tópicos y este punto de vista caracterizarían el resto de la carrera de García Márquez. Más específicamente, la advertencia de que el autor no va a ser "un hombre de buena voluntad" (su generación ha sido engañada y engañará a su vez en reacción) significa que él no será ni liberal ni conservador, que no acepta las reglas del juego nacional, sino que busca otras perspectivas más amplias (Martin, 2012, p. 33).

En esta columna la referencia animal viene al servicio de una imagen: García Márquez describe "ese fuelle nostálgico, amargamente humano, que tiene tanto de animal triste". El fuelle que se mueve lento o rápido, perezoso o con vértigo, aparece a los ojos del narrador como un animal triste, y estas dos palabras envuelven en melancolía un instrumento bulloso.

Esa aura se refuerza con las alusiones femeninas. El texto habla de música "al oído de las mujeres derrumbadas" y agrega que “... Él hizo de lino crudo, de cáñamo indómito, el sueño de la hembra a quien le ardía el hipo en el corazón y tenía, sin embargo, la dolorosa certidumbre de que nunca bajaría hasta su cintura". La imagen femenina que aparece en esta columna ya no es la de la abuela sabia, sino la de la mujer derrumbada: la mujer que tiene ilusión en el corazón, pero sabe que esa ilusión "nunca bajará hasta su cintura". Las alusiones femeninas confirman la imagen de animal triste y concluyen con otra alusión femenina sobre el fuelle que va "desdoblando su vientre en todos los puertos"; el acordeón es una prostituta: una mujer derrumbada que se ofrece al mejor postor. El acordeón no es una exquisitez que se guarda para la élite, sino un instrumento popular que se entrega a quien lo quiera acoger. 
Resulta llamativo que los giros acústicos utilizados por el autor en las dos primeras columnas desaparezcan en esta, que trata precisamente de un instrumento musical. Es una lección literaria: el autor no quiere ser redundante. Las alusiones sonoras sobre el acordeón serían fáciles y, por lo tanto, opta por utilizar las referencias femeninas y animales con otros propósitos distintos al de la descripción del sonido. En este texto las referencias sirven para acentuar el carácter nostálgico y popular del instrumento al que rinde homenaje.

\section{Mientras el consejo de seguridad discute... (El Universal, domingo 23 de mayo de 1948)}

Si lo que caracteriza los comentarios, crónicas o columnas de esta primera época de García Márquez es una suma de palabras bien escritas sobre un tema vacuo, este texto es el ejemplo perfecto. El futuro nobel dedica seis párrafos y 495 palabras a un asunto de moda femenina, que además no es noticia de coyuntura (no se refiere a un desfile o a un diseñador): el texto alude a la moda reciente de alargar la falda femenina 10 centímetros en un movimiento que el autor considera "un retorno inesperado al pretérito".

Este comentario dedicado a las faldas gira, por su tema, en torno al universo femenino. Menciona otra vez a "nuestras abuelas", al igual que en el texto sobre el amanecer, e incluye frases como "nuestras mujeres", "las mujeres, fieles a la eterna política de la coquetería", "alguna aburrida secretaria de oficina", "la nuestra es una mujer intemporal", "nuestras muchachas, con su elasticidad" y "desde la cintura de la novia". Incluye, además, la infaltable alusión animal, que aparece otra vez para reforzar una referencia acústica: “Nuestro 'viernes' será el que se curvó sobre su vientre y puso en él su oído para sentir el tropel de una lejana cabalgata".

La mujer es, otra vez, un colectivo plural que se construye en frases como "nuestras abuelas" y "nuestras mujeres". La mayoría de las referencias hablan de la mujer en plural (muchachas, mujeres, abuelas) e incluyen un elemento común, distinto al de las mujeres de las columnas anteriores: acá aparece con claridad la mujer como cuerpo deseado; la mujer objeto de deseo. Habla, entonces, de la esposa, la novia, el vientre, el tobillo, la rodilla y lo que implica en este universo de deseos que la falda tape o muestre 10 centímetros de más o de menos. La referencia a las abuelas es puntual: alargar la falda implica un retorno al puritanismo, "a la recatada vanidad de nuestras abuelas". La mujer del presente, por oposición al pasado, es la mujer que muestra sus piernas. El autor, que se describe como miembro del sexo feo, o "de este lado del sexo", plantea con su columna una hipótesis: el hombre tiene derecho a mirar. 


\section{Yo podría decir: ya vienen los helicópteros... (El Universal, miércoles 26 de mayo de 1948)}

Este texto es, otra vez, un ejercicio de escritura alrededor de un tema alejado de la coyuntura y, además, de la cotidianidad de la vida costeña. Se trata de una oda a los helicópteros, en 421 palabras distribuidas en seis párrafos: "Lo poético, lo musical del helicóptero, es lo poco que tiene de máquina y lo mucho que tiene de colibrí". No hay una referencia a un helicóptero en particular ni a un hecho concreto que explique el origen de la columna. Al contrario, su origen parece ser la pura liberalidad del autor, pues, como lo señala Jacques Gilard (1981), "es una nota dominada por el empleo del modo condicional, con lo que proclama formal y constantemente la intrínseca arbitrariedad del género" (1981, p. 43).

Además del uso del modo condicional, que resulta tan extraño en una columna de opinión, García Márquez remata con esta sentencia, que es toda una declaración de estilo: "Yo podría decir todas estas cosas y mucho más, y quedar al final con la desolada certidumbre de no haber dicho nada".

El autor incluye tres referencias animales: habla de los helicópteros como un "pájaro fantástico" que lleva a los hombres "por encima de los camellos" y llama la atención sobre "lo poco que tiene de máquina y lo mucho que tiene de colibrí". Asimismo, el texto trae referencias femeninas: “... una gravidez frutal" y "una madre dormida". Las referencias animales son relaciones a partir del vuelo (los pájaros) y de lo exótico o fantástico (los camellos). Las alusiones femeninas están asociadas a la maternidad y las utiliza para describir una aldea (con vida en su interior) que se divisa desde un helicóptero.

Aparece, entonces, otra versión de mujer, distinta a la abuela sabia, la prostituta y el cuerpo deseado. Acá García Márquez alude a la madre, fuente de vida.

\section{Crucificado en la mitad de la tarde está el espantapájaros... (El Universal, jueves 27 de mayo de 1948)}

Héctor Rojas Herazo escribe una columna sobre el desprestigio de los fantasmas y al día siguiente Gabriel García Márquez responde con 377 palabras en seis párrafos sobre la decadencia de los espantapájaros, que considera más digna, porque su poder de disuasión de los pájaros invasores se renueva en cada cosecha: las aves solo aprenden que el espantapájaros es un artefacto cuando ya el muñeco no hace falta.

Lo interesante es el interés que este fallido artilugio despierta en el lector. Descubrir que el espantapájaros está hecho de trapo es el privilegio de los 
pájaros. Creer que los trapos pueden engañar es el privilegio superior de los humanos. Don Quijote se confunde y ve castillos en los mesones pobres de Castilla. Se necesita haber leído mucho para especializarse en ese tipo de locura. García Márquez propone un quijotismo transitorio. Sin acudir al delirio, descubre el agua tibia (Villoro, 2012, p. 132).

En esta columna otra vez García Márquez se refiere a las aves, alusión que resulta natural por ser un texto sobre espantapájaros. El autor escribe frases como "los pájaros jubilosos", el "animal de terror" y alusiones a "las aves descubren, bruscamente, que no hay nada que temer". Más interesante resulta la alusión femenina para reforzar una imagen: el campo al que le han ya recogido los frutos está "con el mismo cansancio glorioso de una recién parida". El posparto aparece acá para ilustrar el momento de la poscosecha, y con esta imagen se entiende mejor la "gravidez frutal" del texto de los helicópteros: el nobel relaciona la vida que ocurre en el vientre materno con los procesos de vida en el mundo vegetal. En estos primeros textos hay alusiones a la semilla, la yerba, los granos, los geranios y otros elementos que, al igual que las alusiones femeninas, y en ocasiones en asocio con ellas, simbolizan los procesos de vida, transformación y muerte que narra el autor.

\section{Un nuevo, inteligente y extraño personaje... (El Universal, sábado 29 de mayo de 1948)}

"Tuérzale el cuello al cisne" es una orden fundamental en el estilo narrativo de Gabriel García Márquez. En Vivir para contarla él se la atribuye al jefe de redacción de El Espectador, José Salgar (García Márquez, 2002, p. 519), y por eso resulta llamativo que la misma frase aparezca publicada en esta columna de mayo de 1948, es decir, al menos seis años antes de su ingreso como periodista al diario capitalino.

Esta columna enigmática de 444 palabras en siete párrafos tiene un origen concreto: Héctor Rojas Herazo hace una caricatura de un personaje, la fija en una pared de la sala de redacción de El Universal y a partir de ahí García Márquez emprende un diálogo que convierte en texto con ese "hombre insignificante" que "tenía sin embargo un gesto señorial".

¿Quién es el hombre de la caricatura? El periodista Alfredo Pernett Morales afirma que se trata del Quijote, quizás porque dentro del texto García Márquez escribe: "Era un curioso retazo de caballeros andantes y de Sanchos decadentes".

El 28 de mayo de 1948 García Márquez entró en conversación con la imagen desmadejada de don Quijote, que el lápiz maestro de Héctor Rojas Herazo (su compañero de redacción y de tempestuosos amaneceres) había colgado de las 
paredes desconchadas donde funcionaban las instalaciones de este periódico. Debió haberse enredado en grandes dificultades al escoger los términos para definir la idea que le bullía en los sesos, porque, comprendiendo sus angustias de sacristán del periodismo, el cuadro de la pared le espetó un párrafo que quiso ser admonitorio, pero se equivocó desde ese momento y hasta siempre. Así le dijo el cuadro: “Usted, señor García, nunca aprenderá a escribir. Tuérzale el cuello a ese cisne decadente. Déjese de tonterías y diga cosas que tengan sustancia. Hay que iniciar una campaña contra la frondosidad lírica. Eliminar esa adjetivación a dos por centavo. Una verdadera labor de sanidad literaria" (Pernett Morales, 2014).

Sin embargo, la caricatura, y por tanto la columna, podría tener como protagonista a Clemente Manuel Zabala, el jefe de redacción de El Universal, quien tiene como función cotidiana hacer lo que García Márquez le atribuye a su personaje: aprobar, corregir o desaprobar los textos para publicar. A Zabala le encajan particularmente bien los dos últimos párrafos del texto:

Este es, en dos platos, el miembro más útil de nuestra redacción. Es el encargado de archivar todo lo que no sirve. Alli en el clavo mismo que sostiene su desgarbada humanidad, está colgada la obra impublicable de todos los Mingos Revulgos espontáneos.

Allí, amigos lectores, pueden encontrar mañana los originales de esta nota.

"Un nuevo, inteligente y extraño personaje" es una columna sobre un hombre concreto, de "carne y hueso", en la que el autor no incluye referencias femeninas. Las animales aparecen en dos frases: una asociada a lo acústico y otra referida, de nuevo, a un ave: "El animal de la timidez se le paseaba por la voz", dice el autor sobre su personaje, y la ya aludida referencia a la famosa frase "tuérzale el cuello a ese cisne decadente".

\section{Frances Drake es una respetable dama... (El Universal, domingo 30 de mayo de 1948)}

La política nacional y la internacional se pasean en este texto de seis párrafos y 469 palabras, escrito en clave de humor y cuyo tema central es el horóscopo. Según García Márquez, desde los romances adolescentes y la paz familiar hasta el desbordamiento de una fuente de agua en Asís, Italia, y el cierre de fronteras del Tíbet tienen su explicación en los oráculos del horóscopo.

No hay que confundir a la señora Frances Drake, autora de los horóscopos que publica El Universal, con Francis Drake, el pirata inglés que el nobel menciona en su primera columna. De hecho, es curioso que en la actualidad los horóscopos de El Heraldo de Barranquilla los firme Frances Drake. 
En esta columna García Márquez alude de nuevo a las aves al hablar de san Francisco de Asís como "el amigo de los pájaros". Sin embargo, las referencias más interesantes vienen desde el lado femenino, porque a los estereotipos de sabia, madre, puta y objeto de deseo acá se suma otra construcción: la bruja. El autor habla de Frances Drake como una "respetable dama norteamericana" y como "esta bruja moderna". La construcción de lo femenino que aparece en este texto viene ligada a lo sobrenatural: la mujer como un sujeto capaz de adivinar el futuro (y escribir el horóscopo) y la mujer como una persona atenta a lo que dicen los horóscopos, "las dueñas de casa dejan una cariñosa y atenta mirada sobre esas columnas para saber a qué temperatura amaneció el mor de sus maridos".

\section{El hecho de que un museo... (El Universal, martes $10^{\circ}$ de junio de 1948)}

Esta breve columna de 355 palabras y cuatro párrafos tiene claro origen en un cable de prensa internacional que informa sobre una exhibición en un museo de Nueva York de un pergamino antiguo, de acuerdo con el cual podría atribuirse a los chinos el invento del cinematógrafo, hace 8000 años. García Márquez parte de este hecho para afirmar que, aunque no es cierto que los chinos hayan inventado el cine, habría sido maravilloso y además posible que lo hubiesen logrado, tal y como hicieron con la pólvora y la brújula. Propone que, ya que no inventaron el cine, este pergamino sirva para designarlos como inventores o bisabuelos de las tiras cómicas.

Sobre esta columna escribe Juan Villoro:

Nada más vulgar que el creador de lo nuevo tenga biografia; resulta más convincente que entregue sus dones al modo de un esquivo profeta. Lo mismo ocurre con la voz narrativa: su autoridad aumenta con aseveraciones que se bastan a sí mismas y no tienen que ser confirmadas (Villoro, 2012, p. 131).

Al igual que el anterior, este artículo alude a una mujer concreta. Cuando el autor dice que "Penny, en lugar de seguir soñando con Robert Taylor..." se refiere a la protagonista de Penny serenade, una película de 1941. Asimismo incluye de nuevo alusiones a las aves ligadas a elementos sonoros cuando escribe "hablaban como cantaban y comían nidos de golondrinas".

\section{Anteayer puso París en vigencia... (El Universal, miércoles 2 de junio de 1948)}

El calendario, y de su mano el tiempo, es el tema central de este texto corto de 345 palabras y seis párrafos. Su origen parece ser un cable internacional en el que se anunciaba que Francia puso en vigor el calendario de la rosa. El 
texto alude al calendario juliano, el gregoriano y el republicano francés, que fue derogado por Napoleón.

Al final García Márquez sugiere que "todo París se haya metido en una página de Platero y yo". Se refiere al capítulo IX, titulado Ronsard, en honor al poeta francés Pierre de Ronsard, de quien Juan Ramón Jiménez transcribe algunos versos sobre las flores de mayo y sus colores.

En este texto el nobel escribe "vivirá París bajo un tiempo femenino", "muchachas cargadas de pétalos" y "una doncella ágil y deportiva". Aparecen de nuevo la mujer como colectivo y la mujer deseada. Asimismo, habla de "nosotros - resignados animales políticos", en una construcción similar a la del "animal triste" del fuelle del acordeón.

Los textos publicados en los días siguientes por García Márquez en El Universal mantuvieron esta característica de incluir alusiones a animales y a figuras femeninas dentro de temas que no necesariamente se relacionaban con esos mundos. Se trata, en últimas, de un periodista de 21 años, sin experiencia previa ni formación específica en el oficio, que gracias a su amplio bagaje lector logra desplegar una variedad de voces narrativas, tiempos y figuras literarias, en las que lo animal y lo femenino toman múltiples formas, como se puede apreciar en la tabla:

\section{Tabla 1. Análisis de microelementos en los 10 textos} periodísticos iniciales de Gabriel García Márquez

\begin{tabular}{|c|c|c|c|c|}
\hline Texto & Voz & Tiempo & $\begin{array}{l}\text { Referencias } \\
\text { animales }\end{array}$ & $\begin{array}{l}\text { Referencias } \\
\text { femeninas }\end{array}$ \\
\hline $\begin{array}{l}\text { 1. Los habitantes } \\
\text { de la ciudad... }\end{array}$ & $\begin{array}{l}\text { Primera persona } \\
\text { del plural. }\end{array}$ & $\begin{array}{l}\text { Pretérito plus- } \\
\text { cuamperfecto. } \\
\text { Pretérito } \\
\text { imperfecto. }\end{array}$ & $\begin{array}{l}\text { Animal } \\
\text { doméstico. } \\
\text { Pájaro eterno. } \\
\text { Gallo grande. }\end{array}$ & \\
\hline $\begin{array}{l}\text { 2. La madrugada } \\
\text {-en su sentido } \\
\text { poético- } \\
\text {.. }\end{array}$ & $\begin{array}{l}\text { Primera persona } \\
\text { del plural. } \\
\text { Tercera persona } \\
\text { del singular. }\end{array}$ & $\begin{array}{l}\text { Pretérito plus- } \\
\text { cuamperfecto. } \\
\text { Pretérito } \\
\text { imperfecto. } \\
\text { Presente } \\
\text { indicativo. }\end{array}$ & $\begin{array}{l}\text { El grillo. } \\
\text { Peces de colores. } \\
\text { Extraños } \\
\text { animales } \\
\text { contradictorios. }\end{array}$ & $\begin{array}{l}\text { Nuestras abue- } \\
\text { las. }\end{array}$ \\
\hline $\begin{array}{l}\text { 3. No sé qué tie- } \\
\text { ne el acordeón... }\end{array}$ & $\begin{array}{l}\text { Primera persona } \\
\text { del singular. } \\
\text { Primera persona } \\
\text { del plural. } \\
\text { Segunda } \\
\text { persona del } \\
\text { singular. }\end{array}$ & $\begin{array}{l}\text { Presente indica- } \\
\text { tivo. } \\
\text { Pretérito imper- } \\
\text { fecto. }\end{array}$ & Animal triste. & $\begin{array}{l}\text { Mujeres } \\
\text { derrumbadas. } \\
\text { El sueño de la } \\
\text { hembra. } \\
\text { Nunca bajaría } \\
\text { hasta su cintura. } \\
\text { Desdoblando su } \\
\text { vientre. }\end{array}$ \\
\hline
\end{tabular}


Comunicación

número 43

Julio - diciembre

2020

\begin{tabular}{|c|c|c|c|c|}
\hline Texto & Voz & Tiempo & $\begin{array}{c}\text { Referencias } \\
\text { animales }\end{array}$ & $\begin{array}{l}\text { Referencias } \\
\text { femeninas }\end{array}$ \\
\hline $\begin{array}{l}\text { 4. Mientras } \\
\text { el Consejo } \\
\text { de Seguridad } \\
\text { discute... }\end{array}$ & $\begin{array}{l}\text { Primera persona } \\
\text { del plural. } \\
\text { Primera persona } \\
\text { del singular. } \\
\text { Tercera persona } \\
\text { del plural. } \\
\text { Tercera persona } \\
\text { del singular. }\end{array}$ & $\begin{array}{l}\text { Presente } \\
\text { indicativo. } \\
\text { Presente } \\
\text { condicional. } \\
\text { Pretérito } \\
\text { imperfecto. } \\
\text { Futuro perfecto. } \\
\text { Futuro } \\
\text { condicional } \\
\text { simple. }\end{array}$ & Lejana cabalgata. & $\begin{array}{l}\text { Mujeres, fieles a } \\
\text { la eterna política } \\
\text { de la coquetería. } \\
\text { Nuestras } \\
\text { abuelas. } \\
\text { Mujer } \\
\text { intemporal. } \\
\text { Aburrida } \\
\text { secretaria de } \\
\text { oficina. } \\
\text { Nuestras } \\
\text { muchachas con } \\
\text { su elasticidad. } \\
\end{array}$ \\
\hline $\begin{array}{l}\text { 5. Yo podría } \\
\text { decir: ya } \\
\text { vienen los } \\
\text { helicópteros... }\end{array}$ & $\begin{array}{l}\text { Primera persona } \\
\text { del singular. } \\
\text { Primera persona } \\
\text { del plural. }\end{array}$ & $\begin{array}{l}\text { Presente } \\
\text { condicional. }\end{array}$ & $\begin{array}{l}\text { Los pájaros. } \\
\text { Los camellos. } \\
\text { Colibrí. }\end{array}$ & $\begin{array}{l}\text { Una gravidez } \\
\text { frutal. } \\
\text { Una madre } \\
\text { dormida. }\end{array}$ \\
\hline $\begin{array}{l}\text { 6. Crucificado en } \\
\text { la mitad de la } \\
\text { tarde... }\end{array}$ & $\begin{array}{l}\text { Tercera persona } \\
\text { del singular. } \\
\text { Primera persona } \\
\text { del singular. } \\
\text { Tercera persona } \\
\text { del plural. }\end{array}$ & $\begin{array}{l}\text { Presente } \\
\text { indicativo. } \\
\text { Futuro perfecto. } \\
\text { Pretérito } \\
\text { perfecto. }\end{array}$ & $\begin{array}{l}\text { Los pájaros. } \\
\text { Animal de terror. } \\
\text { Las aves. }\end{array}$ & $\begin{array}{l}\text { Una recién } \\
\text { parida. }\end{array}$ \\
\hline $\begin{array}{l}\text { 7. Un nuevo, } \\
\text { inteligente } \\
\text { y extraño } \\
\text { personaje... }\end{array}$ & $\begin{array}{l}\text { Primera persona } \\
\text { del plural. } \\
\text { Tercera persona } \\
\text { del singular. }\end{array}$ & $\begin{array}{l}\text { Pretérito } \\
\text { perfecto simple. } \\
\text { Pretérito } \\
\text { imperfecto. } \\
\text { Presente } \\
\text { perfecto simple. }\end{array}$ & $\begin{array}{l}\text { El animal } \\
\text { de la timidez. } \\
\text { Cisne decadente. }\end{array}$ & \\
\hline $\begin{array}{l}\text { 8. Frances } \\
\text { Drake es una } \\
\text { respetable } \\
\text { dama... }\end{array}$ & $\begin{array}{l}\text { Tercera persona } \\
\text { del singular. } \\
\text { Primera persona } \\
\text { del plural. }\end{array}$ & $\begin{array}{l}\text { Presente } \\
\text { perfecto simple. } \\
\text { Pretérito } \\
\text { imperfecto. } \\
\text { Condicional } \\
\text { perfecto. }\end{array}$ & $\begin{array}{l}\text { Amigo } \\
\text { de los pájaros. }\end{array}$ & $\begin{array}{l}\text { Esta bruja } \\
\text { moderna. } \\
\text { Las dueñas } \\
\text { de casa. }\end{array}$ \\
\hline $\begin{array}{l}\text { 9. El hecho de } \\
\text { que un museo... }\end{array}$ & $\begin{array}{l}\text { Primera persona } \\
\text { del plural. }\end{array}$ & $\begin{array}{l}\text { Presente } \\
\text { perfecto. } \\
\text { Pretérito } \\
\text { perfecto. }\end{array}$ & $\begin{array}{l}\text { Nidos de golon- } \\
\text { drinas. }\end{array}$ & Penny. \\
\hline $\begin{array}{l}\text { 10. Anteayer } \\
\text { puso París en } \\
\text { vigencia... }\end{array}$ & $\begin{array}{l}\text { Primera persona } \\
\text { del plural. } \\
\text { Tercera persona } \\
\text { del singular. }\end{array}$ & $\begin{array}{l}\text { Pretérito } \\
\text { perfecto. } \\
\text { Pretérito } \\
\text { imperfecto. } \\
\text { Presente } \\
\text { perfecto. }\end{array}$ & $\begin{array}{l}\text { Animales } \\
\text { políticos. }\end{array}$ & $\begin{array}{l}\text { Bajo un tiempo } \\
\text { femenino. } \\
\text { Muchachas } \\
\text { cargadas de } \\
\text { pétalos. } \\
\text { Una doncella } \\
\text { ágil y deportiva. }\end{array}$ \\
\hline
\end{tabular}




\section{Algunas consideraciones finales}

La producción escrita de Gabriel García Márquez fue amplia y diversa. Después de las columnas iniciales, escribió crónicas, reportajes, cuentos, novelas, textos dramáticos, ensayos y guiones de cine. Decir que su obra literaria se encuentra reunida en estos 10 primeros textos que suman 4043 palabras puede ser pretencioso, pero sí es claro que en ellos está el germen del estilo narrativo que caracterizaría su obra posterior.

El joven escritor no tenía aún borradores de Cien años de soledad, El amor en los tiempos del cólera, Crónica de una muerte anunciada, El otoño del patriarca, La hojarasca, El amor y otros demonios (de ninguna de las obras que posteriormente le dieron reconocimiento). Aunque no tuviera en mente estos títulos concretos, la lectura de estas columnas sí revela elementos estilísticos claros sobre las formas narrativas que caracterizaron su obra posterior, así como sus preocupaciones temáticas.

En lo estilístico, las columnas de Punto y Aparte muestran cómo García Márquez utiliza adjetivos y sustantivos para construir atmósferas míticas o fantásticas a partir de la cotidianidad: ancianos barbudos, catástrofes, oráculos y leyendas forman parte de sus recursos narrativos. También hay un uso particular del humor y la irreverencia, basado en el estilo de las greguerías de Ramón Gómez de la Serna. Hay un llamativo manejo del "nosotros" en vez del "yo" que permite rastrear el origen de esas obras posteriores, de sagas familiares e historias colectivas y plurales.

Al humor irreverente y el interés consciente por la temporalidad se suma un tercer elemento estilístico: frecuentes referencias a fantasmas, ancianos barbudos, antepasados, catástrofes, espectáculos de leyenda, el primer hombre y pájaros fantásticos, en textos que tienen su origen en la vida de Cartagena o en los cables internacionales y en el fragor diario de la actualidad periodística. Esta característica evidencia un interés temprano del escritor por trascender la frontera de lo noticioso y crear un universo simbólico para, desde el lenguaje, construir otras posibilidades paralelas a la realidad: lo real maravilloso, lo macondiano se empieza a vislumbrar en el tono de estos escritos iniciales.

Pasar de un fragmento como "el hechizo de las alfombras mágicas que con solo oír su voz se llevaban al hombre por encima de los camellos", que incluye en su quinta columna, y llegar años más tarde a Remedios, la Bella, que se eleva volando entre sábanas blancas, es cuestión de trabajo estético en una dirección que ya había empezado a trazar. 
Pero quizás el rasgo estilístico más importante de estas primeras columnas es la preocupación por el "cómo" decir, por encima del "qué". La confesión de su quinta columna, que termina diciendo que puede quedar "con la desolada certidumbre de no haber dicho nada", revela a un joven autor muy consciente del poder de la palabra, que le permite expresarse con gracia, "decir todas estas cosas y mucho más", y mantener el interés del lector no tanto por el asunto narrado, sino por la forma narrativa: el estilo es el sello del escritor.

En una época anterior a internet, que un escritor de apenas 21 años pueda incluir tantas referencias a personajes y a la cultura popular nacional e internacional muestra una voracidad cultivada no solo por la literatura en particular y las artes en general, sino también una actitud abierta a la conversación y la tertulia con gentes que le abrieron el mundo hacia ámbitos tan diversos y cosmopolitas, a pesar de haber viajado tan poco hasta aquel entonces.

Esa variedad se refleja en sus intereses temáticos: en un contexto de censura, con censores instalados en la sala de redacción, el autor escribe textos que giran en torno a temas y geografías varias, donde pueden caber desde la silla eléctrica y el toque de queda hasta las faldas femeninas o los espantapájaros. No hay temas que le resulten indiferentes o inabordables; el joven escritor muestra conocimientos amplios y maestría para hilar asuntos aparentemente inconexos, pero que terminan relacionados. Sus novelas, como Cien años de soledad, reflejan esa misma intención de totalidad y universalidad, así se trate de historias que ocurran en una aldea, palabra que también aparece en estos textos iniciales.

Resulta interesante observar cómo en estos primeros textos García Márquez construye un universo femenino particular, con mujeres "frutales" de senos amplios y alusiones a su gravidez y su vientre. Se trata de mujeres de un carácter fuerte, autónomo. Sobre la negra de la columna 16, que empieza con la frase En el lado opuesto al mío vieje viajando la negra, escribe: "Pocas cosas tienen tanta belleza plástica como una negra engreída. Esta parece saberlo y, aparentemente, desprecia al compañero de asiento que aspira su vecindad como un perfume amargo, inalcanzable". Varias de las mujeres que el nobel presenta en estas columnas son así: altivas e inalcanzables, como casi todas las protagonistas de su narrativa de ficción.

El indio, la negra, el músico, el anciano barbudo, las mujeres frutales, las abuelas, las muchachas, el espantapájaros, la escritora de horóscopos, el dictador...: la variada gama de personajes que habitan estos primeros textos también ayuda a identificar algunos intereses del autor en la construcción de los protagonistas de sus posteriores obras de ficción, y no solo por los prototipos señalados, sino por las formas en las que el autor describe los 
rasgos más notables de sus personajes: "La negra viaja con todo el cuerpo, con la boca redonda y maciza, llena de una madurez frutal; con los ojos centelleantes, con su total organismo de negra convencida", fragmento de la columna número 16, perfectamente podría formar parte de un cuento o una novela.

García Márquez calificó estos primeros textos como "carpintería diaria", "gimnasia" y "material alimenticio sin compromiso histórico", expresiones que dejan ver cierto tono de desdén frente al valor periodístico o literario de aquellos. Es posible que las cimas alcanzadas con su obra lo hayan llevado a desestimar estos textos de formación, pero cualquier persona que se haya acercado a sus obras más conocidas podrá identificar en ellos unos rasgos que permitían vislumbrar intereses temáticos y estilísticos. La búsqueda de esas primeras huellas en estas columnas iniciales no exige grandes dosis de arqueología: los rastros que dejó el autor son visibles y están por todas partes.

\section{Referencias}

Abad Faciolince, H. (2012). El feliz mamagallista desdichado. En Gabo periodista. Antología de textos periodísticos de Gabriel García Márquez. Fundación para el Nuevo Periodismo Iberoamericano.

Arango, G. (2013). Un ramo de nomeolvides. García Márquez en El Universal. Editorial Universidad Pontificia Bolivariana.

Araújo Fontalvo, O. (2015). El legado de Macondo. Antología de ensayos críticos sobre Gabriel García Márquez. Editorial Universidad del Norte.

Feliciano, H. (2012). Gabo periodista. Antología de textos periodísticos de Gabriel García Márquez. Fundación para el Nuevo Periodismo Iberoamericano.

Galvis, S. (1996). Los García Márquez. Arango Editores.

Gilard, J. (1981). Prólogo. En G. García Márquez, Obra periodística. Textos costeños [Vol. 1]. Bruguera.

García Márquez, G. (1996, 7 de octubre). El mejor oficio del mundo. Palabras pronunciadas ante la 52 Asamblea de la Sociedad Interamericana de Prensa en Los Ángeles. http:/ / especialgabo.fnpi.org/las-ideas-de-gabo/el-mejor-oficio-del-mundo/

García Márquez, G. (2002). Vivir para contarla. Norma.

García Usta, J. (2007). García Márquez en Cartagena: sus inicios literarios. Seix Barral. Giorgi, G. y Rodríguez, F. (2007). Ensayos sobre biopolítica. Excesos de vida. Paidós.

Ludmer, J. (2009). Literaturas postautónomas 2.0. Propuesta Educativa, (32), año 18, 41 a 45.

Martin, G. (2012). Gabriel García Márquez: una visión panorámica. En Gabo periodista. Antología de textos periodísticos de Gabriel García Márquez. Fundación para el Nuevo Periodismo Iberoamericano.

Nascimento, E. (2016). Para un concepto de literatura en el siglo XXI: expansiones, heteronomías, desdoblamientos. En El lugar de la literatura en el Siglo XXI. Ediciones Universitarias de Valparaíso. 
Pernett Morales, A. (2014, 27 de abril). De reportero en El Universal a Premio Nobel de literatura. El Universal. http:/ / www.eluniversal.com.co/cultural/de-reportero-en-eluniversal-premio-nobel-de-literatura-158042

Rodríguez Amaya, F. (2015). Crónica y ficción en Gabriel García Márquez. Fuentes de una vocación universal, 1947-1953. En El legado de Macondo. Antología de ensayos críticos sobre Gabriel García Márquez. Editorial Universidad del Norte.

Sims, R. (1988). Periodismo, ficción, espacio carnavalesco y oposiciones binarias: la creación de la infraestructura novelística de Gabriel García Márquez. Hispania, 71 (1), 50-60. http: / / www.jstor.org/stable/343193

Villoro, J. (2012). Cuando la madrugada era verdad. Gabo periodista. Antología de textos periodísticos de Gabriel García Márquez. Fundación para el Nuevo Periodismo Iberoamericano.

\section{Las primeras 10 columnas}

García Márquez, G. (1948, 21 de mayo). Los habitantes de la ciudad nos habíamos acostumbrado... El Universal.

García Márquez, G. (1948, 21 de mayo). La madrugada -en su sentido poético-... El Universal.

García Márquez, G. (1948, 22 de mayo). No sé qué tiene el acordeón... El Universal.

García Márquez, G. (1948, 23 de mayo). Mientras el Consejo de Seguridad discute... El Universal.

García Márquez, G. (1948, 26 de mayo). Yo podría decir: ya vienen los helicópteros... El Universal.

García Márquez, G. (1948, 27 de mayo). Crucificado en la mitad de la tarde... El Universal. García Márquez, G. (1948, 29 de mayo). Un nuevo, inteligente y extraño personaje... El Universal.

García Márquez, G. (1948, 30 de mayo). Frances Drake es una respetable dama... El Universal. García Márquez, G. (1948, 1. ${ }^{\circ}$ de junio). El hecho de que un museo... El Universal.

García Márquez, G. (1948, 2 de junio). Anteayer puso París en vigencia... El Universal. 